Nig. J. Pure \& Appl. Sci. Vol. 34 (Issue 2, 2021)
e-ISSN 2756-4045
(C) 2021 Faculty of Physical Sciences and Faculty of
www.njpas.com.ng

\title{
Mixed Aqueous Surfactants Solution for Rapid Oil Extraction from Palm Kernel Seed
}

\author{
${ }^{1}$ Baba Makun, ${ }^{1}$ Kamoru Adio Salam*, ${ }^{1}$ Abdullahi Mohammed Evuti, ${ }^{2}$ Tunde.F. Adepoju
}

Page | $4050{ }^{1}$ Department of Chemical Engineering, Faculty of Engineering, University of Abuja, Main Campus, Airport Road, P.M.B. 117, Abuja, FCT, Nigeria.

${ }^{2}$ Department of Chemical/Petrochemical Engineering, Akwa-Ibom State University, Akwa-Ibom State, Nigeria.

Date Received: 02-05-2021

Date Accepted: 25-09-2021

DOI: https://doi.org/10.48198/NJPAS/21.xxx

\section{ABSTRACT}

Adverse effects associated with the use of hexane or other similar organic extraction solvents for extracting oil from oilseeds have been a drive for alternative less toxic oil extracting solvents. This research focuses on oil extraction from grinded palm kernel using solution of mixed aqueous polyoxythylene (23) lauryl ether (BRIJ-35) and sodium dodecyl sulphate (SDS) surfactants and sodium chloride ( $\mathrm{NaCl}$ ) as the electrolyte. Grinded Biomass was agitated in the solution of the mixed surfactant, allowing the extracted oil to be liberated from the seeds as separate phase from the aqueous phase. The effect of SDS concentration, $\mathrm{NaCl}$ concentration, contact time and liquid/seed ratio on oil yield was studied. The extracted oil was subjected to Fourier Transform Infrared Spectroscope (FT-IR) characterization to determine the functional groups present in the oil. At optimum conditions for the mixed aqueous surfactant extraction $(0.2379$ wt.\% SDS, 0.5995 wt. $\%$ BRIJ-35, 0.3wt. $\% \mathrm{NaCl}, 10 \mathrm{ml} / \mathrm{g}$ liquid/solid ratio, $25 \mathrm{~min}$ contact time at $25^{\circ} \mathrm{C}$ ), an optimum $78 \%$ oil yield was obtained. In contrast, at $50^{\circ} \mathrm{C}$ for $24 \mathrm{hr}$, an optimum of $81 \%$ and $82 \%$ oil yield were obtained respectively when hexane and petroleum ether were used as oil extracting solvents. Addition of BRIJ-35 and $\mathrm{NaCl}$ to the SDS solution improved the oil yield. Oil extracted using mixed aqueous surfactants, petroleum ether and hexane have the same functional groups indicating the surfactant does not affect the quality of the oil extracted.

Keywords: Surfactant; hexane; petroleum ether; palm kernel; extraction

\section{Introduction}

Fuels from fossil sources are irreversibly depleting and combustion from this fuel source has negative environmental effect. Prevention of environmental pollution and energy crisis associated with the use of this fuel source as complete source of energy has been a major drive for the search for sustainable oil extraction from oil-seeds for biofuel production. Over 350 oilbearing crops are available as potential biofuel feedstock but soybean (Glycine max), rape seed (Brassica napus), sunflower (Helianthus annuus), and oil palm fruit (Elaeis guineensis) are among the few which had been commercialized (Demirbas, 2005).

Extraction of oil from oilseeds is predominantly by solvent and mechanical extraction. Solvent

\section{Corresponding Author: Kamoru Adio Salam}

Department of Chemical Engineering, Faculty of Engineering, University of Abuja, Main Campus, Airport Road, P.M.B. 117, Abuja, FCT, Nigeria.

Phone: +2348104629145; Email: kamoru.salam@uniabuja.edu.ng: kamorusalam@gmail.com 
extraction of edible oil from their seeds, i.e., peanut (Arachis hypogaea), soybean, corn (Zea mays), sunflower, and palm kernel using hexane as solvent has been commercialized (Naksuk et al., 2009). However, because of the volatility of Page | 4051 hexane the process requires expensive equipment to ensure workers safety. United State Environment Protection Agency (2005) classified hexane as a hazardous air pollutant and vegetable oil extraction plants being a major contributor. Moreso, per tons of oil extracted, it is estimated that $0.7 \mathrm{~kg}$ of hexane is usually released into the environment.

Exposure to this hazardous compound at $125 \mathrm{ppm}$ for three months causes peripheral nerve damage, muscle wasting, and atrophies (Pauzan et al., 2013). Owing to this, alternative technologies are needed to eliminate the use of toxic solvents including hexane (Tyson et al., 2004). Oil extraction by solution of aqueous surfactant is one of the promising alternatives. Few researchers have demonstrated the feasibility of application of aqueous-based oil extraction (Hagenmaier, 1974; South well and Harris, 1992; Evon et al., 2007). $\mathrm{Wu}$ et al. (2011) used enzyme-assisted aqueous extraction to demulsified oil-rich emulsion and obtained $88 \%$ yield out of the $90 \%$ total oil available. Raman et al. (2003) demonstrated the feasibility of formation of micro emulsion by mixture of non-ionic surfactant with palm kernel oil and its derivatives. The principal salts used are $\mathrm{NaCl}, \mathrm{CaCl}_{2}$, and $\mathrm{KCl}$. Monovalent salts are, however, preferred since divalent ions can cause surfactant precipitation (Negin et al., 2017). Salts impact the electrostatic repulsions of the head groups in the case of ionic surfactants (Doan et al., 2003) but also the steric repulsion between tails (He et al., 2014).

In all those studies, extractions that are microemulsion based were evaluated as an alternative to hexane, for the extraction of vegetable oil and the approach is considered a clean technology since surfactants utilized for the extraction are biodegradable and non-toxic. This method is based on the formation of micro emulsion induced by reduction of surface tension between the oil vegetable seeds and the aqueous extracting system. The reduction in the surface tension occurs as a result of inclusion of the surfactant in the aqueous medium.

Edible oil that contains triglycerides may be difficult to form a micro emulsion with, but this problem can be minimized by selecting a suitable surfactant extended and lipophilic linker (Komesvarakul et al., 2006; Do and Sabatini, 2010). Hsu and $\mathrm{Nacu}$ (2003) reported the behavior of soybean oil in a water emulsion stabilized by non-ionic surfactant. Micro emulsion formation of eucalyptus oil by mixed non-ionic surfactant, polyoxythylene (23) Lauryl ether (Brij 35) and anionic surfactant (AOT) using butanol alcohol as linker was reported (Rajib and Bidyut, 2005). Mixed surfactant systems are more efficient than solo surfactant systems (Salager et al., 2019).

In order to prevent competition in using oil for food or fuel, a feedstock with less competition on food such as palm kernel seed is more attractive. In addition, oil extraction from palm kernel using mixed aqueous solution of sodium dodecyl sulphate (SDS) and polyoxythylene (23) lauryl ether (Brij 35) has not been reported in the literature to the best of our knowledge.

\section{Materials and Methods}

The Biomass was sourced from a local oil palm plantation in Minna, Niger State, Nigeria. Surfactants used are: Sodium dodecyl suphate, SDS (anionic surfactant), 98\% purity; polyoxythylene (23) Lauryl ether (non-ionic surfactant), 95\% purity; and sodium chloride (an electrolyte). All were obtained from Sigma Aldrich, UK and used as received.

\section{Sample Preparation}

De-hulled Biomass was washed to remove all dirt and unwanted substances. After which it was oven-dried at $100^{\circ} \mathrm{C}$, thereafter, it was grinded into granules of particle size $\leq 0.5 \mathrm{~mm}$. The Biomass 
was kept inside a desiccator to avoid adsorption of moisture.

\section{FT-IR characterization of the oil extracted}

The functional groups present in the extracted oil Page | 4052 using hexane, petroleum ether and aqueous solution of mixed sodium dodecyl suphate (SDS) and BRIJ-35 were identified by FT-IR spectroscope in the range of $4,000-500 \mathrm{~cm}^{-1}$ using FTIR-8400S, Shimadzu. The oil samples were mixed with oven-dried spectroscopic grade $\mathrm{KBr}$ and pressed into a disk (Bakar et al., 2016).

\section{Oil Extraction}

\section{Solvent based Extraction}

$50 \mathrm{~g}$ of the grinded Biomass seed was weighed using a digital weighing balance and then wrapped with a filter paper. Then it was inserted into the extraction chamber (thimble) of the Soxhlet extractor. The solvent (hexane or petroleum ether) was filled into the $500 \mathrm{ml}$ round bottom flask and the extraction was conducted at $50^{\circ} \mathrm{C}$ for $24 \mathrm{~h}$ (Pauzan et al., 2013). After the extraction, the solvent was evaporated from the solvent-oil mixture until constant mass. All extraction experiments were conducted in duplicates. The oil yield was computed using equation 1 (Pauzan et al., 2013). The above procedure was repeated using petroleum ether as extraction solvent.

Extraction yield $=\frac{\text { Mass of Extracted oil }}{\text { Mass of Biomass }} \times 100 \% \quad$ Eq. 1

\section{Mixed surfactant-based Extraction}

$1 \mathrm{~g}$ of the grinded Biomass seed with particle size $\leq 0.5 \mathrm{~mm}$ was weighed using a digital weighing balance. After which, it was mixed with $20 \mathrm{~mL}$ of aqueous surfactant solution concentrations varied from 0.2163-0.2595 wt \% SDS; concentration of BRIJ 35 was fixed at 0.5995 wt $\%$. The concentration of Sodium chloride was varied from $0-1 \mathrm{wt} \%$ while liquid/solid ratio was varied from $4-$ $10 \mathrm{ml} / \mathrm{g}$ to investigate their respective effects on oil extracted yield. The mixture was allowed to agitate on a rotary shaker at $150 \mathrm{rpm}$ for a specified contact time (0-35min) (Pauzan et al., 2013). At the end of each contact time, the mixture was centrifuged to separate the surfactant and the extracted oil from the residual solid. The efficiency of the oil extracted was calculated using equation 1.

\section{Results}

\section{Effect of SDS concentration on oil yield}

Fig 1 shows the effect of SDS concentration on oil yield. There was an increment in oil yield from 30 to $38 \%$ as the concentration of SDS increased from 0.2163 to $0.2379 \mathrm{w} \%$. The oil yield reduced to $30.5 \%$ as a result of further increase in SDS concentration from 0.2379 to $0.2595 \mathrm{w} \%$. This result suggests that there was an increment in oil extraction yield as the SDS concentration increased owning to reduction in interfacial tension caused by increase in micelle concentration. The oil yield peaked at $0.2379 \mathrm{wt} \%$ SDS concentration and further increase in concentration reduced oil yield possibly due to solubilization of the free oil into the micelle (Pauzan et al., 2013).

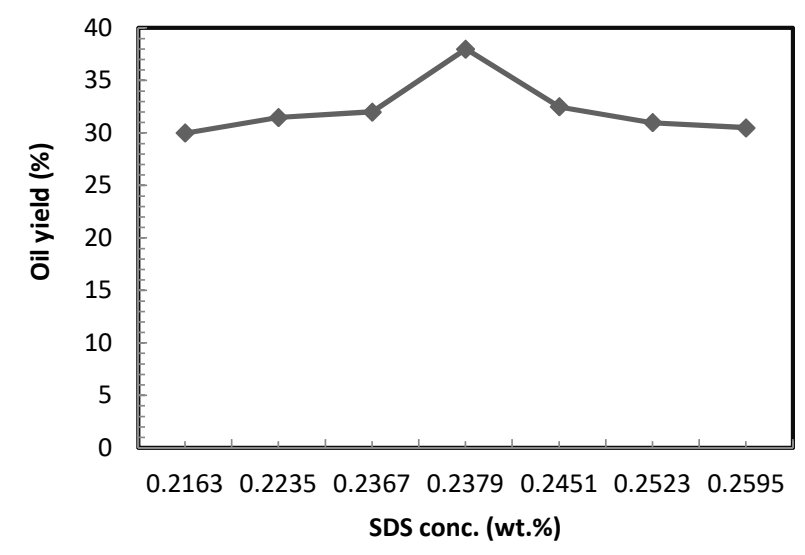

Fig 1: Graph of efficiency against Anionic surfactant concentration

Conc. of surfactant (0.2163-0.2595) wt. \%, contact time $(1 \mathrm{~min})$, grain size $(0.212 \mathrm{~mm})$, mass of seed $(1 \mathrm{~g})$, temperature $\left(25{ }^{\circ} \mathrm{C}\right)$, agitation (150rpm). 


\section{Effect of mixed aqueous SDS and BRIJ 35 on oil yield}

Fig. 2 shows the effect of mixed SDS and BRIJ35 on oil yield. BRIJ-35 (non-ionic surfactant) Page | 4053 concentration was fixed at 0.5995 wt.\% while the concentration of SDS was varied from 0.2163 to 0.2595 wt. $\%$. BRIJ-35 addition to SDS increased the oil yield moderately from 53 to $56 \%$ compared to a maximum of $38 \%$ oil yield obtained when 0.2379 wt.\% SDS was used alone. The interaction between the anionic surfactant SDS at 0.2379 wt. $\%$ and $0.5995 w t . \%$ BRIJ-35 caused an increase in the yield as shown in Fig. 2. This trend could be as a result of inclusion of BRIJ-35 to SDS reduced the interfacial tension more than SDS alone and thereby caused an increase in liberation of the oil from the seed. Again, further increase in the concentration of SDS above $0.2379 \mathrm{wt} \%$ resulted into decrease in oil yield due to solubilization of the extracted oil into the micelles formed by mixture BRIJ-35 and SDS (Pauzan et al., 2013).

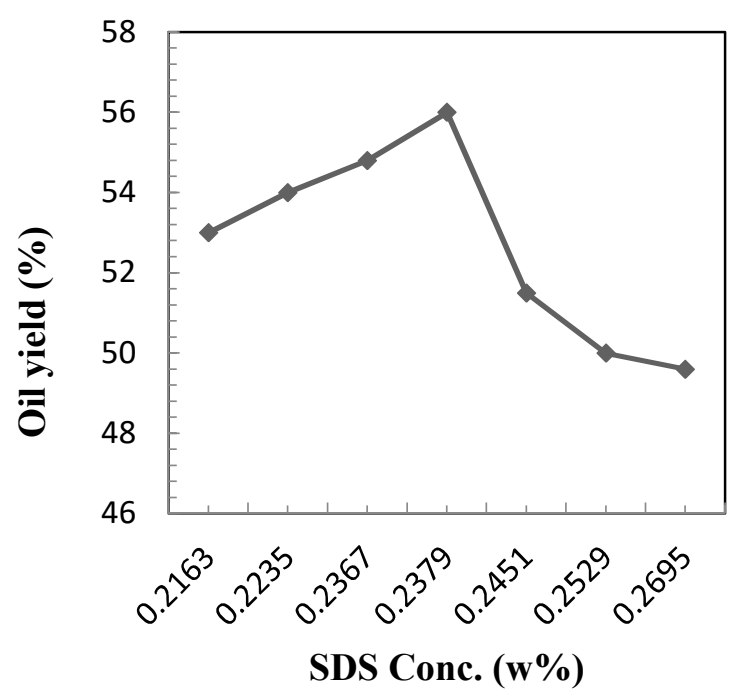

Fig. 2: Effect of SDS concentration on oil yield

SDS conc. (0.2163-0.2695 w\%), BRIJ-35 conc. $(0.5995 \mathrm{w} \%)$, contact time $(1 \mathrm{~min})$, grain size $(0.212 \mathrm{~mm})$, mass of seed $(1 \mathrm{~g})$, temperature $(25$ ${ }^{\circ} \mathrm{C}$ ), agitation (150rpm).

\section{Effect of sodium chloride on oil yield}

Fig. 3 shows the effect of $\mathrm{NaCl}$ concentration on oil yield. The concentration of the salt was varied from 0 to $1 \mathrm{w} \%$ while SDS concentration was fixed at $0.2379 \mathrm{w} \%$ and BRIJ-35 at $0.5995 \mathrm{w} \%$. There was a moderate increase in oil yield to $59 \%$ at $0.3 \mathrm{wt} \%$ concentration of salt, as a result of the addition of sodium chloride to the mixed surfactant solution. Sodium chloride is an electrolyte and helps in lowering the interfacial tension of surfactant solution (Naksuk et al., 2009). It usually decreases the HydrophileLipohile Balance (HLB) of an ionic surfactant system. Decrease in HLB of the system decreases interfacial tension suggesting why the oil yield slightly increased. However, excessive increase in the concentration of $\mathrm{NaCl}$ above 0.3 wt.\% resulted in a decrease in the oil yield possibly owning to solubilization of the oil extracted into the surfactant micelle as shown in Fig. 3

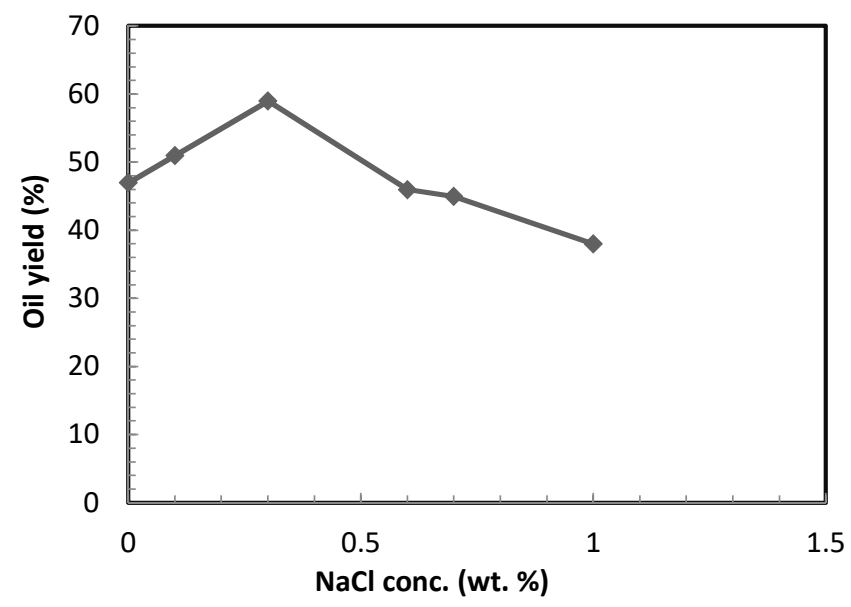

Fig. 3: Effect of $\mathrm{NaCl}$ on oil yield

Conc. of SDS surfactant (0.2379 wt.\%), Conc. of BRIJ-35(0.5995 wt.\%), Conc. of $\mathrm{NaCl}$ (0-1.0 wt. $\%)$, Contact time $(1 \mathrm{~min})$, grain size $(0.212 \mathrm{~mm})$, mass of seed $(1 \mathrm{~g})$, temperature $\left(25^{\circ} \mathrm{C}\right)$, agitation (150rpm). 


\section{Effect of contact time on oil yield.}

Fig. 4 illustrates the effect of contact time on the oil yield. Increase in the contact time produced positive effect on the oil yield. Oil yield increased from 63 to $70.5 \%$ as the contact time increased from 1 to $25 \mathrm{~min}$. However, further increase in contact time to 35 min steadily decreased the oil yield to $67.6 \%$. This result conforms to the findings of Naksuk et al. (2009) where they obtained maximum oil yield in $30 \mathrm{~min}$ with further increase in contact time caused decrease in oil yield. The reduction in the oil yield at high contact time could be as a result of solubilization of the free oil extracted into the micelle.

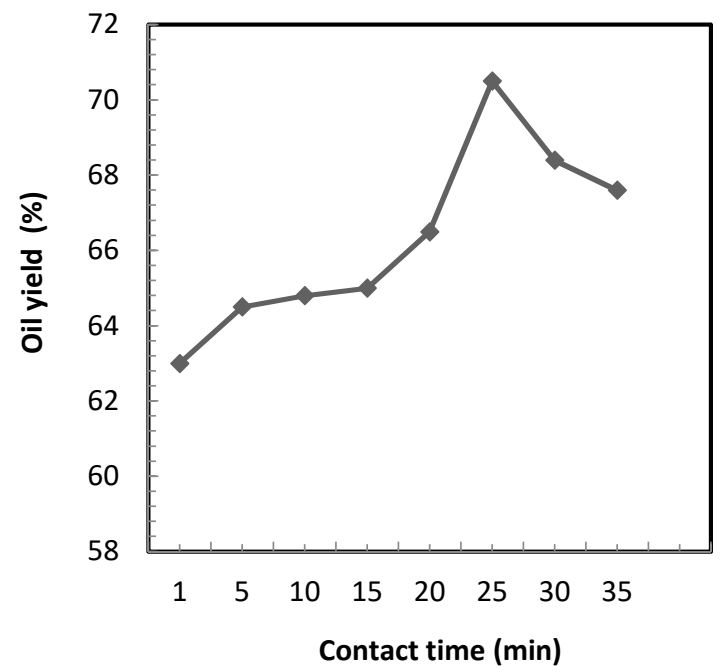

Fig. 4: Effect of contact time on oil yield.

Conc. of SDS surfactant (0.2379 wt.\%), conc. of BRIJ-35(0.5995 wt.\%), Conc. of $\mathrm{NaCl}(0.3$ wt.\%), contact time (1-35min), grain size $(0.212 \mathrm{~mm})$, mass of $\operatorname{seed}(1 \mathrm{~g})$, temperature $\left(25^{\circ} \mathrm{C}\right)$, agitation $(150 \mathrm{rpm})$.

\section{Effect of liquid/solid ratio on oil yiel}

Fig 5 illustrates the effect of liquid-solid ratio on the oil yield. There was an oil increase in oil yield from 65 to $78.4 \%$ as the liquid-solid ratio increased from 4 to $10 \mathrm{ml} / \mathrm{g}$. Further increase in the liquid/solid ratio to $12 \mathrm{ml} / \mathrm{g}$ caused slight reduction in the oil yield to $76 \%$. This result conforms to other findings (Witthayapanyanon et al., 2006). Again, the decrease in the amount of oil extracted at the highest liquid/solid ratio could be as a result of lower ineffective mixing, since the agitation rate was fixed at $150 \mathrm{rpm}$. In addition, excessive high liquid/solid ratio could reduce particle collision, resulting to low oil yield.

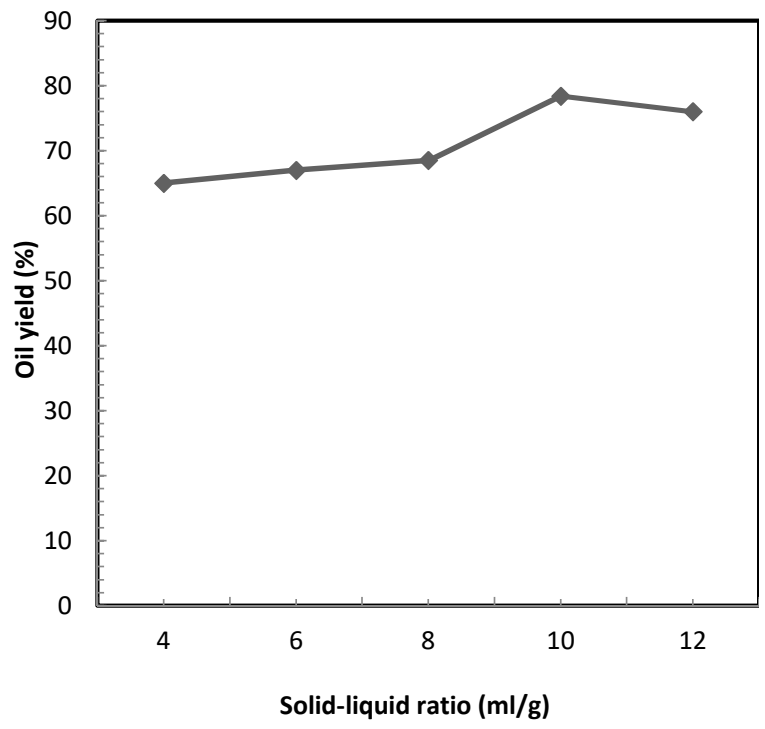

Fig. 5: Effect of solid-liquid ratio on oil yield

Conc. of SDS surfactant (0.2379 wt.\%), Conc. of BRIJ-35(0.5995 wt.\%), Conc. of $\mathrm{NaCl}$ (0.3 wt.\%), Contact time (25min), grain size $(0.212 \mathrm{~mm})$, mass of seed $(1 \mathrm{~g})$, temperature $\left(25^{\circ} \mathrm{C}\right)$, agitation $(150 \mathrm{rpm})$.

\section{Mixed aqueous surfactant versus solvent based extraction}

Solvent-based extraction method using petroleum ether and hexane was done once optimum conditions were obtained by extraction using mixed aqueous surfactant solution. A $50.0 \mathrm{~g}$ of the Biomass seed was used and the extraction was run for a period of $24 \mathrm{hrs}$ to get all the extractable oil from the seed. Petroleum ether and 
hexane were used in this extraction to ascertain the solvent that will produce the highest yield since both are favorable in extracting oil. The average extraction efficiency using hexane and petroleum ether are $82 \%$ and $81 \%$ respectively.

Page | 4055 At optimum extraction conditions for the aqueous surfactant extraction, $0.2379 \mathrm{w} \%$ SDS, 0.5995 w\% BRIJ-35, 0.3 w\% NaCl, $10 \mathrm{ml} / \mathrm{g}$ liquid/solid ratio at $25 \mathrm{~min}$ were utilized to obtain $78.4 \%$ yield. Although the oil yield obtained using solvent based system is slightly higher than surfactant-based extraction, it is interesting to note that the surfactant-based extraction required $25 \mathrm{~min}$ to achieve the maximum $78.4 \%$ yield while hexane or petroleum ether used $24 \mathrm{~h}$. to extract the maximum $81 \%$ and 82 respectively.

\section{FT-IR characterization of the oil extracted}

Fig. 6 illustrates the superimposed FT-IR spectra of the extracted oil using hexane, petroleum ether and aqueous solution of mixed sodium dodecyl suphate (SDS) and BRIJ-35. The graph shows that there is no significant difference from the superimposed spectra suggesting that the mixed surfactant did not affect the quality of the extracted oil.

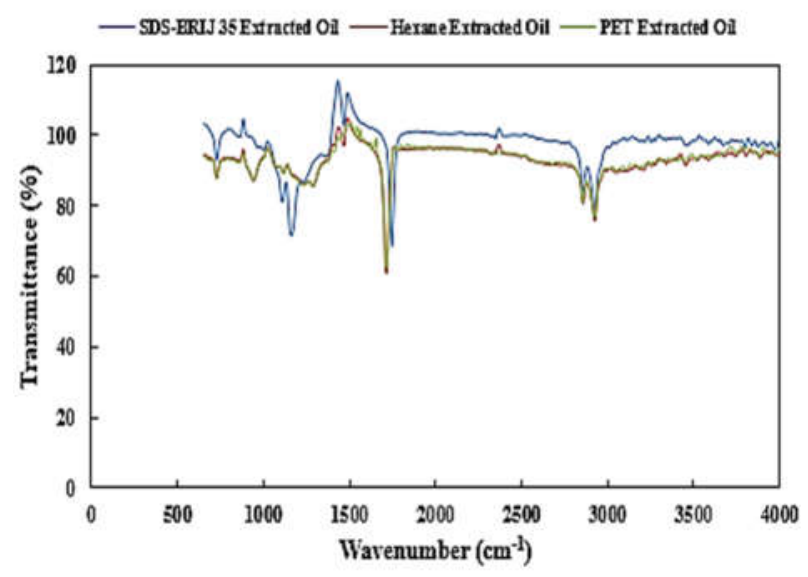

Fig. 6: Spectrum of and SDS vs BRIJ-35 Hexane, Petroleum ether superimposed.
Table 1: Major peaks of the FT-IR Spectrum of the oi extract

\begin{tabular}{|c|c|c|}
\hline $\begin{array}{l}\text { Wave number } \\
\text { (cm-1) }\end{array}$ & Assignment & Reference \\
\hline 2924 & $\begin{array}{l}\text { Methylene C-H } \\
\text { stretch }\end{array}$ & Coates (2000) \\
\hline 2916 & $\begin{array}{l}\text { Methylene C-H } \\
\text { stretch }\end{array}$ & Coates (2000) \\
\hline 2862 & $\begin{array}{l}\text { Methylene C-H } \\
\text { stretch }\end{array}$ & Coates (2000) \\
\hline 1736 & $\begin{array}{l}\mathrm{C}=\mathrm{O} \text { carbonyl } \\
\text { functional group }\end{array}$ & Coates (2000) \\
\hline 1713 & $\begin{array}{l}\mathrm{C}=\mathrm{O} \text { carbonyl } \\
\text { functional group }\end{array}$ & Coates (2000) \\
\hline 1465 & $\begin{array}{l}\text { Methylene C-H } \\
\text { bending }\end{array}$ & Coates (2000) \\
\hline 1150 & C-O stretch & Coates (2000) \\
\hline
\end{tabular}

Table 1 shows the major peaks and the assignments for the spectra. The peaks at 2924, 2916 and $2862 \mathrm{~cm}^{-1}$ is assigned to methylene C-H stretches while the peak at $1465 \mathrm{~cm}^{-1}$ is assigned to methylene $\mathrm{C}-\mathrm{H}$ bending. The peaks at 1736$1713 \mathrm{~cm}^{-1}$ are assigned to carbonyl functional groups. The peak at $1150 \mathrm{~cm}^{-1}$ is assigned to $\mathrm{C}-\mathrm{O}$ stretch originated from $\mathrm{C}-\mathrm{O}-\mathrm{C}$ of the carboxylic acid bonded to glycerol backbone of the triglyceride. All the functional groups are those expected from triglyceride which is the major components of the extracted oil.

\section{Conclusions}

This research demonstrates the possibility of using a mixed aqueous surfactant solution of SDS and BRIJ-35 as alternative to organic solvent based extraction for extracting oil from palm kernel. At optimum conditions for the aqueous mixed surfactant extraction $(0.2379$ wt. $\%$ SDS, 0.5995 wt.\% BRIJ-35, 0.3wt.\% NaCl, 10 ml/g liquid/solid ratio, $25 \mathrm{~min}$ contact time at $25^{\circ} \mathrm{C}$ ), a maximum $78.4 \%$ oil yield was obtained. In contrast, at $50^{\circ} \mathrm{C}$ for $24 \mathrm{hr}$, a maximum of $81 \%$ and $82 \%$ oil yield were obtained respectively when hexane and petroleum ether were used as oil extracting solvents. Addition of BRIJ-35 and $\mathrm{NaCl}$ to the SDS aqueous solution improved the oil yield. 
Although the extraction efficiency is lower than extraction using solvent, the process requires shorter time and lower temperature than solventbased extraction method. The extraction technology studied is more environmentally

Page | 4056 friendly. However, the challenge in aqueous mixed surfactant oil extraction is solubilization of the extracted oil inside the surfactant making separation difficult at high surfactant concentration. Therefore, low mixed surfactant concentration is suggested to reduce separation difficulty and further screening of more surfactants for this process is recommended.

\section{Acknowledgements}

Authors appreciate Biochemistry Department, Federal University of Technology, Minna, for allowing us to use some of their research facilities.

\section{Competing Interest}

I hereby declare that the author has no affiliations or financial involvement with anybody or organization with a financial interest or conflict with the subject or material discussed in this manuscript

\section{References}

Amira, S.M.P., Nor Bainun, B.I. and Nur Syafiqah, A.B.M.Z. (2013). Microemulsion-Based Palm Kernel and Peanut Oil Extraction using Nonionic Surfactant Brij 30 Solution. Malaysian Journal of Chemistry, 15 (1), 006 - 012.

Bakar, N.A., Cui, H., Abu-Siada, A.and Li, S. A review of spectroscopy technology applications in transformer condition monitoring. In Proceedings of the International Conference on Condition Monitoring and Diagnosis (CMD), Xi'an, China, 25-28 September (2016).

Coates, J. (2000). Interpretation of Infrared Spectra, A Practical Approach. In Meyers, R.A. Ed., Encyclopedia of Analytical
Chemistry, John Wiley and Sons Ltd., Chichester.

Demirbas A. (2005). Biodiesel production from vegetable oils via catalytic and noncatalytic supercritical methanol transesterification methods. Prog. Energy and Combustion Sc. 31 (5-6), 466-487.

Doan, T., Acosta, E., Scamehorn, J. F. and Sabatini, D. (2003). Formulating middlephase microemulsions using mixed anionic and cationic surfactant systems. J Surf Deterg 6, 215-224.

Do, L.D. and Sabatini, D.A. (2010). Aqueous extended-surfactant based method for vegetable oil extraction: proof of concept. Journal of the American Oil Chemists' Society, 87(10), 1211-1220.

Evon, P., Vandenbossche, V., Pontalier, P.Y., and Rigal, L. (2007). Direct extraction of oil from sunflower seeds by twin-screw extruder according to an aqueous extraction process: Feasibility study and influence of operating conditions. Ind. Crops Prod. 26, 351-359.

Hagenmaier, R.D. (1974). Aqueous processing of full-fat sunflower seeds: yields of oil and protein. J. Am. Oil Chem. Soc. 51, 470-471.

He, Z. Q., Zhang, M. J., Fang, Y., Jin, G. Y. and Chen, J. (2014). Extended surfactants: a well-designed spacer to improve interfacial performance through a gradual polarity transition. Coll Surf A: Physicochem Eng Asp 450, 83-92.

Hsu, J.P. and Nacu, A. (2003). Behavior of soybean oil-in-water emulsion stabilized by nonionic surfactant. J. Colloid Interface Sci. 259, 374-381.

Komesvarakul, N., Szekeres, S.E., Acosta, E.J., Faller, J.F., Mentlik, T., Fisher, L.B., 
Nicoll, G., Sabatini, D.A., and Scamehorn, J.F. (2006). Microemulsions of triglyceride-based oils: the effect of co-oil and salinity on phase diagrams. J. Cosmet. Sci., 55, 309-325.

Mattil, K.F., Norris, F.A., and Swern, D. (1964). Extraction of fats and oils. In: Swern, D. (Ed.), Bailey's Industrial Oil and Fat Products. Third ed. John Willey \& Sons, London, pp. 637-717.

Naksuk, A., Sabatini, D.A. and Tongcumpou, C. (2009). Microemulsion-Based Palm Kernel Oil Extraction Using Mixed Surfactant Solutions. Journal of Industrial Crops and Products, 30, 194-198.

Negin, C., Ali, S., and Xie, Q. (2017). Most common surfactants employed in chemical enhanced oil recovery. Petroleum 3, 197211.

Rajib, K.M., and Bidyut, K.P. (2005). Physicochemical investigations of micro emulsification of eucalyptus oil and water using mixed surfactants (AOT + Brij-35) and butanol. J. Colloid Interface Sci., 283, 565-577.

Raman, I.A., Suhaimi, H., and Tiddy, G.J.T. (2003). Liquid crystals and microemulsion formed by mixture of a non-ionic surfactant with palm oil and its derivatives. Adv. Colloid Interface $\quad$ Sci., 106, 109127.

Salager, J. L., Forgiarini, A.and Marquez, R. (2019). Extended surfactants including an alkoxylated central part intermediate producing a gradual polarity transition - A review of the properties used in applications such as enhanced oil recovery and polar oil solubilization in microemulsions. J Surf Deterg 22, 935972.

Southwell, K.H., and Harris, R.V. (1992). Extraction of oil from oilseeds using the hot water floatation method. Trop. Sci., 32, 251-262.Tyson, K.S., Bozell, J., Wallace, R., Peterson, E., and Moens, L. (2004). Technical Report: Biomass Oil Analysis Research Needs and Recommendation. Midwest Research Institute, Battelle.

United State Environmental Protection Agency (2005). Air emission information [online]. Available form: [8 March 2005].

Witthayapanyanon A., Acosta E.J., Harwell J.H. and Sabatini D.A. (2006). Formulation of ultralow interfacial tension systems using extended surfactants. Journal of Surfactants and Detergents, 9 (4), 331339.

Wu, H., Jiang, L., Zhu, X., Wu, H. and Li, Y. (2011). Microemulsion Fermentation Simultaneous Extraction Processing of Oil and Protein from Soybean. Journal of Advanced Materials Research, 156-157, 1059-1068. 